\title{
Motivação para aprender: o autorrelato de professores brasileiros e chilenos
}

\author{
Sandra Maieski - Universidade Estadual de Londrina, Londrina, Paraná, Brasil \\ Katya Luciane de Oliveira - Universidade Estadual de Londrina, Londrina, Paraná, Brasil \\ José Aloyseo Bruneck - Universidade Estadual de Londrina, Londrina, Paraná, Brasil
}

\begin{abstract}
Resumo
Foi objetivo deste estudo verificar a percepção de professores de duas realidades culturais diferentes: Brasil e Chile, quanto às qualidades do comportamento motivado ou desmotivado de seus alunos para aprender. Trata-se de um estudo do tipo descritivo com delineamento de levantamento e tratamento por meio da análise de conteúdo. Participaram 16 professores do ensino fundamental, sendo 7 brasileiros e 9 chilenos. Os dados foram mensurados, mediante de uma entrevista aberta com o professor e categorizados de acordo com os comportamentos motivado e desmotivado apresentados pelos alunos na visão de seus professores. Para tanto, geraram-se dados inerentes ao comportamento motivado e desmotivado apresentado pelos alunos na visão de seus professores. Os dados revelaram muita semelhança na forma como os professores das duas realidades culturais percebem as qualidades relacionadas ao comportamento motivado ou desmotivado de seus alunos. A discussão dos resultados levantados se dá em termos de algumas implicações educacionais.

Palavras-chave: Motivação, Ensino fundamental, Expectativas do professor.
\end{abstract}

Motivation to learn: measuring the self-report of brazilian and chilean teachers

\begin{abstract}
The objective of this study was to verify the teachers' perception from two different cultural realities: Brazil and Chile, about the qualities of the motivated or demotivated behavior to learn of their students. It is a descriptive study with a survey and treatment delineation through the content analysis. 16 elementary school teachers participated in this study: 7 Brazilians and 9 Chileans. The data was measured through an open interview with the teacher and these were categorized. For this, inherent data was created about the motivated and demotivated behavior shown by the students according to the teachers view. The data revealed considerable similarity in the way the teachers from the two cultural realities perceive the qualities related to the motivated or demotivated behavior of their students. The discussion of the data collected is given in terms of their educational implications for the two investigated cultural realities.

Keywords: Motivation, Teacher Action, Elementary School.
\end{abstract}

Motivación para aprender: medida del auto-relato de profesores brasileños y chilenos

\begin{abstract}
Resumen
Fue el objetivo de este estudio verificar la percepción de profesores de dos realidades culturales distintas: Brasil y Chile, en cuanto a las cualidades del comportamiento motivado o desmotivado de sus alumnos para aprender. Se trata de un estudio de tipo descriptivo, con delineamiento de levantamiento y tratamiento por medio de análisis de contenido. Participaron 16 profesores de la enseñanza básica, siendo 7 brasileños y 9 chilenos. Los datos fueron medidos por medio de una entrevista abierta con el profesor y categorizados. Para eso, se generaron datos inherentes al comportamiento motivado y desmotivado presentado por los alumnos en la visión de sus profesores. Los datos revelaron mucha semejanza en la forma como los profesores de las dos realidades culturales perciben las cualidades relacionadas al comportamiento motivado o desmotivado de sus alumnos. La discusión de los resultados levantados se da en términos de sus implicaciones educacionales para las dos realidades culturales investigadas.

Palabras-clave: Motivación, Acción docente, Enseñanza básica.
\end{abstract}

Contemporaneamente, a educação se caracteriza pela formação do capital humano, numa lógica voltada para a satisfação de interesses privados (Saviani, 2008). Manchope (2010) esclarece que investir em capital humano é imprescindível para a produtividade. Para tanto, o indivíduo deve destacar-se pela inovação, criatividade e autonomia. O professor possui um papel determinante, uma vez que a ele cabe "despertar a criatividade, desenvolver a autonomia, estimular o rigor intelectual e criar as condições necessárias para o sucesso da educação formal e da educação permanente" (p. 90). Portanto, a qualidade da educação está diretamente ligada à qualidade dos profissionais que nela atuam.
No tocante à ação docente, cabe ressaltar que os profissionais da educação enfrentam problemas que afetam diretamente a qualidade do processo de ensino e aprendizagem. Manchope (2010) ressalta que atualmente se podem destacar três questões fundamentais. A primeira se refere à relação professoraluno, a segunda à relação professor e sociedade e a terceira ao plano individual. Como a intenção deste trabalho é o estudo da influência do professor no estilo motivacional do aluno, abordar-se-á somente a primeira relação. A autora afirma que a tarefa dos educadores é tornar a escola um espaço atraente para o aluno que chega à educação formal com uma gama de 
informações muito grande, que acabam entrando em concorrência com os conteúdos escolares.

O relatório para a UNESCO da Comissão Internacional sobre a Educação para o século XXI destaca que, se nesse período o professor apresentar uma formação deficiente ou estiver pouco motivado, haverá um prejuízo para as futuras aprendizagens, uma vez que essas não possuíram uma base sólida (Delors, 1999). A repercussão dessa premissa se fez sentir na LBDEN 9.394/96, a atual Lei de Diretrizes e Bases da Educação Brasileira. Segundo essa legislação, o professor que atua nos anos iniciais da educação básica deve possuir formação de nível superior. No tocante à realidade chilena, os profissionais da educação devem possuir o título de professor concedido pelas Escolas Normais, Institutos Profissionais ou Universidades e os que são estrangeiros devem convalidar seus documentos de acordo com as disposições vigentes na legislação (Chile, 1992).

Bzuneck e Guimarães (2004) destacam que uma característica inerente às aprendizagens escolares é que elas ocorrem numa condição grupal, na qual há a influência do professor e das inúmeras formas de interação que acontecem entre este e os alunos e entre os alunos. Contudo, afirma Boruchovitch (2004), os adultos e, no caso específico os professores, devem proteger as crianças contra distrações e interferências que dificultam a realização de tarefas. Para a autora, aos adultos cabe a função de evitar interromper a criança e encorajar outras a fazerem o mesmo, criar desafios apropriados à faixa etária em que se encontra a criança para que ela possa experimentar sucesso.

Quando se aborda o papel do professor na motivação para aprender, na perspectiva da teoria da Autodeterminação, é fundamental o auxílio que o docente dispensa à criança para que ela vá satisfazendo as necessidades psicológicas básicas de todo o ser humano. Boruchovitch (2004) considera que a criança que pede ajuda o faz porque realmente necessita de auxílio ou porque quer chamar a atenção. A autora ressalta a importância de que a assistência prestada pelo professor à criança contribua para preservar a competência percebida e o senso de controle, encorajando a independência no desempenho futuro. Dispensar auxílio em excesso promove a dependência, ao invés de comportamentos autorregulados e mais motivados (Nelson-Legall \& Glor-Scheidb, 1986).

No que concerne às tarefas atribuídas à criança, Stipek (1998) afirma que essas devem ser significativas e ligadas ao mundo real. Nessa direção, autores como Ames (1992), Bandura, Azzi e Polydoro (2008), Bzuneck (2010), Bzuneck e Guimarães (2004), Maehr (1984) e Szymanski (2010) salientam a importância de que as tarefas sejam organizadas de modo que a criança possa perceber seu progresso, sentir-se eficaz e no controle da situação. Portanto, aqui se evidencia a relevância do senso de competência e de autonomia, em que o indivíduo se considera autor da ação.

Nesse sentido, Bronson (2000) cita outras ações pertinentes ao professor, tais como a utilização de métodos que propiciem ao aluno a oportunidade de escolha, forneçam apoio para as ideias individuais e estilos pessoais de desempenho e utilizem critérios controláveis de avaliação, enfatizem os resultados individuais em oposição a comparações, evidenciem o esforço e o progresso, apresentar o erro como oportunidade de aprendizagem e oportunizem ao aluno repetidas chances de revisar o trabalho, visando alcançar a meta estabelecida.

Aspectos relacionados à avaliação incidem diretamente na qualidade motivacional do aluno ou geram desmotivação. Boruchovitch (1999; 2004), Bronson (2000), Brophy (1999) e Bzuneck (2010) argumentam que avaliações vagas ou gerais prejudicam a criança, pois não fornecem a ela informações sobre sua própria competência. Sendo assim, o feedback do adulto contribui para promover um maior grau de autorregulação quando é centrado em aspectos específicos da tarefa. Brophy (1981; 1999), Deci e Ryan (2000), Hancock (2002), Henderlong e Lepper (2002) e Pintrich e Schunk (2002) alertam que o uso de métodos externos de controle e a oferta de recompensas e punições que fortalecem o controle externo exercem efeitos negativos na motivação intrínseca. Para Boruchovitch (2004) e Bzuneck e Guimarães (2010) o excesso de controle externo diminui o senso de responsabilidade, por exemplo, contribuindo para a evitação de desafios e para diminuição da persistência. Bandura e colaboradores (2008) evidenciam o quanto a autorregulação para aprender auxilia eficazmente a obtenção de sucesso.

Cabe ao professor conduzir o aluno a refletir sobre suas ações durante o processo de aprendizagem. Esse estímulo, no entanto, não significa levantar questões para que o aluno pense sozinho. $\mathrm{O}$ trabalho docente deve ser guiado pela interação professor-aluno a todo tempo: antes, durante e depois da realização das atividades, num processo de análise e avaliação contínua do alcance ou não da meta pretendida.

Guimarães, Bzuneck e Borichovitch (2003), Hagger, Chatzisarantis e Harris (2006), Reeve, Deci e Ryan (2004) e Ryan e Deci (2006) salientam que as intervenções mais frutíferas são as que agem conjuntamente nos processos cognitivos, metacognitivos, motivacionais e afetivos. Destacam ainda a importância de que os contextos de sala de aula continuem a requisitar, apoiar e estimular a 
manutenção dos componentes trabalhados nas intervenções.

Portanto, despertar e cultivar o senso de competência e a autonomia são aspectos que o professor deve perseguir em seu trabalho docente para motivar o aluno a aprender (Rufini, Bzuneck \& Oliveira, 2011). Contudo, satisfazer a necessidade de pertencimento do aluno é também uma meta que o professor deve buscar. Perceber-se aceito faz com que o aluno se torne mais motivado e comprometido com a própria educação. Consequentemente, pode-se esperar um melhor aproveitamento e melhores resultados de aprendizagem (Anderman \& Anderman, 1998; Baumeister \& Leary, 1995; Deci \& Ryan, 1985; 2000; Guimarães, 2004; Osterman, 2000).

Segundo Pintrinch e Schunk (2002) possuir uma intenção é o ponto inicial para toda e qualquer atividade humana. Quando se referencia no tocante ao contexto escolar, essa intenção é muitas vezes inexistente o que acarreta, consequentemente, a falta de motivação ou, mais precisamente, a desmotivação para aprender (Bzuneck \& Guimarães, 2010). McCombs e Pope (1994) atestam que pesquisas no campo motivacional demonstraram que, apesar da motivação ser algo inerente ao ser humano, ela deve ser cultivada. Bzuneck (2009) ressalta que a motivação aparece como um objeto altamente complexo. Para Stipek (1998), a motivação é causa geradora, mantenedora e condutora das ações que movem o indivíduo na concretização de uma intenção.

Goya, Bzuneck e Guimarães (2008) destacam que a motivação atualmente é um dos problemas enfrentados no campo educacional. Segundo os autores, professores motivados, entusiasmados tendem a influenciar seus alunos para uma aprendizagem eficaz. O contrário também é verdadeiro: professores desmotivados não são capazes de despertar em seus alunos uma aprendizagem de qualidade.

Bzuneck e Guimarães (2004) sugerem aos professores o uso de estratégias para a motivação, tais como proporcionar tarefas desafiadoras e dosadas às capacidades dos alunos, pois afirmam que todo o desafio desequilibra e incentiva o trabalho mental e afugenta pensamentos de comparação com os outros. Quanto às situações de fracasso, os autores alertam que essas nunca devem ser atribuídas à falta de capacidade, pois essa atribuição acarreta a diminuição da crença de autoeficácia, um elemento importantíssimo para novas tentativas de acerto, conforme propõe a teoria Social Cognitiva.

A primeira tarefa do professor na motivação do aluno para aprender é remediadora, ou seja, o professor deve recuperar alunos desmotivados ou orientar alunos portadores de alguma forma de motivação distorcida, se assim forem diagnosticados. A segunda função dos professores é preventiva e de caráter permanente, salienta o autor. Essa ação tem como foco toda a classe ao longo de todo o ano letivo, implantando e mantendo otimizada a motivação para aprender. Tratase de um trabalho complexo, que exige conhecimentos, habilidades e muito senso de comprometimento com a educação (Bzuneck, 2009; Goya \& colaboradores, 2008)

Posto isso, não há como negar a importância do papel desenvolvido pelo professor na motivação para aprender. Tanto a literatura como os resultados de pesquisas que buscam desvelar a influência que $\mathrm{o}$ professor exerce em sala de aula, no conjunto da mesma e em cada indivíduo pessoalmente, é notório o alcance e a repercussão de suas ações e/ou omissões. Contudo, a intervenção do professor junto a seus alunos, seja de caráter remediador ou preventivo e permanente, como sugere Bzuneck (2009; 2010), Bzuneck e Guimarães (2007) e Machado (2009), só é possível a partir do momento em que ele consegue detectar entre seus alunos aqueles que apresentam comportamento motivado, para mantê-lo, ou desmotivado, para revertê-lo. Para tanto, faz-se necessário que o professor saiba detectar quais qualidades fazem parte do comportamento motivado e quais se referem ao comportamento desmotivado.

No intuito de investigar a existência de pesquisas relativas à motivação para aprender em âmbito nacional, tomando como ponto de partida o ano de 2005, foram encontrados alguns estudos. O levantamento do estado da arte revelou a existência de dez trabalhos, que serão citados por ordem cronológica: Costa (2005), Genari (2006), Dias, Enumo \& Turini (2006), Rodrigues e Barrera (2007), Cunha, Sisto e Machado (2006), Zolnier (2007), Cardoso (2008), Souza e Brito (2008) Paiva e Boruchovitch (2010) e Peres (2011).

No que concerne a estudos referentes à motivação para aprender no Chile, a pesquisa do estado da arte tomando como ponto de partida o ano de 2005 revelou a existência de apenas três estudos: dois com estudantes universitários (Fernández Gonzáles, Martinez-Conde Beluzan \& Melipillán Araneda, 2009; Villalobos, Mujica, González-Pienda, Pérez \& Rosário, 2009) e um com crianças com paralisia cerebral (Rosas, Pérez-Salas \& Olguín, 2010). Pelo exposto, fica evidente a inexistência de estudos relativos à motivação de alunos da educação básica chilena para aprender. Segundo Zulma (2006), o tema está muito presente na literatura psicológica dos últimos anos e são raros os textos que atualmente não dedicam algumas páginas a esse conceito. Contudo, parece não serem tratados com profundidade. 
Em vista da inexistência de estudos, seja no contexto educacional chileno, seja no brasileiro, quanto à percepção do professor no que se refere ao comportamento motivado ou desmotivado de seus alunos para aprender, foi desenvolvido este estudo no intuito de verificar essa percepção nas duas realidades culturais investigadas: Brasil e Chile. Trata-se de um estudo do tipo descritivo com delineamento de levantamento e tratamento qualitativo com análise de conteúdo que geram dados percentuais para discussão dos dados.

\section{Método}

\section{Participantes}

Participaram do estudo 16 professoras da primeira etapa do ensino fundamental $\left(1^{\circ}\right.$ ao $5^{\circ}$ anos), sendo $56,25 \%(n=9)$ chilenas e $43,75 \%(n=7)$ brasileiras do estado do Paraná, todas do sexo feminino. Das professoras chilenas participantes, 55,5\% $(n=5)$ eram da escola privada e 44,5\% (n=4) da escola pública. Com relação ao número de professoras brasileiras envolvidas no estudo, $57,1 \% \quad(n=4)$ eram da escola privada e $42,9 \%(n=3)$ da escola pública. Cabe também esclarecer que, embora todas as professoras do ensino fundamental das escolas avaliadas tivessem sido convidadas, apenas foram recebidas avaliações de 16 professoras. Considerando que as professoras investigadas sejam brasileiras ou chilenas, eram todas dos anos iniciais do ensino fundamental, as disciplinas que lecionavam eram: matemática, língua materna, ciências, geografia e história, com uma média de 16 anos de exercício da docência. No tocante à formação, todas possuíam graduação.

\section{Instrumentos}

Para constatar a percepção dos professores quanto às qualidades do comportamento motivado ou desmotivado para aprender de seus alunos, foi realizada uma entrevista aberta. A entrevista foi elaborada por Maieski e Oliveira (2011). Inicialmente aos professores foi solicitado o preenchimento de um formulário contendo dados pessoais, tais como: sexo, idade, titulação, anos de atuação como professor, disciplinas que leciona. A entrevista continha uma questão fechada e uma questão aberta. Também é importante mencionar que o professor foi orientado a pensar em alunos motivados e aqueles desmotivados para aprender, segundo sua percepção. Assim sendo, na questão fechada o professor deveria assinalar se considerava o aluno que ele pensou motivado ou desmotivado para aprender (Você considera esse aluno que você pensou motivado ou desmotivado para aprender?). $\mathrm{Na}$ questão aberta, o professor deveria mencionar comportamentos apresentados por seus alunos mediante os quais ele poderia caracterizá-los como motivados ou desmotivados para aprender (Por favor, cite comportamentos apresentados por esse aluno que você pensou que o levam a crer que ele é motivado/desmotivado para aprender). O instrumento utilizado, portanto, foi do tipo narrativo, sob forma escrita.

\section{Procedimentos}

Inicialmente a pesquisa foi aprovada pelo Comitê de Ética da Universidade Estadual de Londrina, sob protocolo número 189/10. Por ocasião do envio ao Comitê de Ética já foi providenciada a autorização das instituições de ensino no Brasil e no Chile.

Para tanto, no Brasil a coleta foi realizada no estado do Paraná em uma escola confessional privada pertencente a uma organização que tem escolas distribuídas em diversos países do mundo, as quais mantêm a mesma proposta educacional. A escolha por uma escola chilena se deveu ao fato de que um dos pesquisadores, após a coleta no Brasil na referida escola, conseguiu uma bolsa de estudos da já citada organização para que pudesse viajar até o Chile, conhecer aquela realidade cultural, bem como a escola privada confessional da mesma rede de ensino.

Quanto à coleta realizada nas escolas públicas brasileira e chilena, no Brasil ela ocorreu em uma escola pública paranaense de porte médio, com aproximadamente 500 alunos distribuídos nos diferentes anos do ensino fundamental. A escola, localizada na região central, recebia alunos cujo perfil socioeconômico era de classe média e classe média baixa. No que se refere à escola pública chilena, esta foi selecionada mediante sugestão dos educadores chilenos que atuavam na escola privada na qual a coleta foi realizada, os quais após tomarem conhecimento do tipo de perfil de escola desejado, perfil este que estivesse o mais próximo possível da realidade da escola pública na qual a coleta foi realizada aqui no Brasil, seleciona a escola. Dessa forma, a escola pública chilena apresentava semelhanças, especialmente, o tipo socioeconômico, com a escola pública brasileira.

Os participantes assinaram o Termo de Consentimento Livre e Esclarecido, mediante o qual eles expressaram sua aceitação em participar da presente pesquisa. Aos professores responsáveis pelas classes do $1^{\circ}$ ao $4^{\circ}$ ano das duas escolas investigadas no Chile e do $1^{\circ}$ ao $5^{\circ}$ ano das duas escolas investigadas no Brasil foram entregues os formulários da entrevista, pois eles manifestaram a preferência por preencher pessoalmente e com tranquilidade os itens da pesquisa. 


\section{Resultados}

Para levantar os dados provenientes de uma entrevista aberta com o professor, estes foram categorizados. Para tanto, geraram-se dados inerentes ao comportamento motivado e desmotivado apresentado pelos alunos na visão de seus professores. Os dados levantados quanto à percepção dos professores acerca do comportamento motivado ou desmotivado apresentado por seus alunos podem ser vistos nas Tabelas 1 e 2 . Cabe mencionar que primeiro serão apresentados os dados inerentes à mensuração da avaliação dos comportamentos motivados e desmotivados dos alunos dos professores das escolas públicas brasileira e chilena e na sequência serão apresentadas as avaliações dos professores das escolas privadas brasileira e chilena. Ver Tabela 1.

Tabela 1. Características dos alunos motivados, no Brasil e no Chile, segundo a percepção dos professores

\begin{tabular}{|c|c|c|c|c|}
\hline \multirow{2}{*}{ Qualidades relacionadas ao comportamento motivado } & \multicolumn{2}{|c|}{ Brasil } & \multicolumn{2}{|c|}{ Chile } \\
\hline & $\mathrm{F}$ & $\%$ & $\mathrm{~F}$ & $\%$ \\
\hline Concentrado & 14 & 11,6 & 20 & 10,9 \\
\hline Questionador & 12 & 10,6 & 2 & 1,0 \\
\hline Participativo & 29 & 24,2 & 41 & 22,0 \\
\hline Coopera com o grupo & 7 & 5,9 & 18 & 9,8 \\
\hline Gosta de desafios & 2 & 1,6 & 4 & 2,1 \\
\hline Curioso & 2 & 1,6 & 7 & 3,9 \\
\hline Alegre & 4 & 3,3 & 4 & 2,1 \\
\hline Tem iniciativa & 3 & 2,5 & 2 & 1,0 \\
\hline Seguro & 1 & 0,8 & 2 & 1,0 \\
\hline Sabe da importância do estudo - aplica o que aprende & 4 & 3,3 & 4 & 2,1 \\
\hline Sabe aproveitar o tempo & 1 & 0,8 & & \\
\hline Responsável & 1 & 0,8 & 17 & 9,2 \\
\hline Realiza atividades complementares não solicitadas em sala de aula & 4 & 3,3 & 1 & 0,5 \\
\hline Persistente & 1 & 0,8 & 4 & 2,1 \\
\hline Paciente & 1 & 0,8 & & \\
\hline Organizado & 4 & 3,3 & 7 & 3,9 \\
\hline Caprichoso & 9 & 7,5 & 8 & 4,3 \\
\hline Ágil em realizar as atividades & 7 & 5,8 & 18 & 9,8 \\
\hline Apresenta excelente desempenho & & & 9 & 4,9 \\
\hline Tem bom relacionamento social & 4 & 3,3 & 4 & 2,1 \\
\hline Competitivo & 1 & 0,8 & 3 & 1,6 \\
\hline Possui apoio dos pais & 4 & 3,3 & 3 & 1,6 \\
\hline Autônomo & & & 1 & 0,5 \\
\hline Faz bom uso do tempo livre & & & 1 & 0,5 \\
\hline Alta autoestima & 5 & 4,1 & & \\
\hline Criativo & & & 3 & 1,6 \\
\hline Disciplinado & & & 2 & 1,0 \\
\hline Comunicativo & & & 1 & 0,5 \\
\hline Total & 120 & 100 & 186 & 100 \\
\hline
\end{tabular}

No que tange à avaliação do comportamento motivado do aluno na visão das professoras brasileiras, foi possível observar que, dos 59 alunos avaliados, isto é, aqueles alunos que os professores pensaram para, na sua percepção, indicar quem eram motivados e desmotivados, $59,3 \% \quad(n=35)$ foram considerados motivados e 40,6\% (n=24) foram considerados desmotivados. A média de idade dos alunos indicados por seus professores foi de 8 anos. Dos alunos considerados motivados, $68,5 \%(n=24)$ eram meninas e $31,5 \%(n=11)$ eram meninos.
A análise da Tabela 1 permite observar que o item participativo foi o mais apontado pelas professoras brasileiras como qualidade para o comportamento motivado. Houve 22 itens, num percentual de 27,2\% do total dos itens mencionados, que possuíram apenas uma ocorrência de citação, tais como responsável, persistente, paciente, dentre outros.

No que tange à avaliação da percepção dos professores chilenos, dos 77 alunos avaliados por seus professores, $54,5 \% \quad(n=42)$ foram considerados portadores de comportamentos motivados e $45,5 \%$ 
$(n=35)$ de comportamentos desmotivados. A média de idade dos alunos avaliados foi de 8 anos, sendo todos do sexo feminino.

Dentre as qualidades apontadas pelos professores chilenos como características do aluno motivado, o item participativo obteve a maior frequência, 41, num total de 25 itens mencionados. Destes, 4 itens receberam apenas uma indicação, perfazendo o total de $16 \%$ do total das qualidades sugeridas.

Tabela 2. Características dos alunos desmotivados, no Brasil e no Chile, segundo a percepção dos professores

\begin{tabular}{lcccc}
\hline \multicolumn{1}{c}{ Qualidades relacionadas ao comportamento desmotivado } & \multicolumn{3}{c}{ Brasil } & \multicolumn{2}{c}{ Chile } \\
\cline { 2 - 4 } & $\mathrm{F}$ & $\%$ & $\mathrm{~F}$ & $\%$ \\
\hline Desinteressado em aprender & 16 & 23,8 & 18 & 15,1 \\
Distraído & 13 & 19,4 & 23 & 19,2 \\
Não possui boa interação social & 3 & 4,5 & 5 & 4,2 \\
Desorganizado com o material & 3 & 4,5 & 7 & 5,6 \\
Não realiza as atividades & 6 & 9,0 & 9 & 7,5 \\
Lento para realizar as atividades & 5 & 7,5 & 14 & 11,6 \\
Falta muito à escola & 2 & 3,0 & 2 & 1,6 \\
Queixa-se de tudo & 1 & 1,4 & 13 & 11,0 \\
Irresponsável & & & 5 & 4,2 \\
Triste & 6 & 9,0 & 2 & 1,6 \\
Indisciplinado & 5 & 7,5 & 12 & 10,1 \\
Inseguro & 1 & 1,4 & 2 & 1,6 \\
Frustra-se com facilidade & & & 1 & 0,8 \\
Não possui apoio dos pais & & & 1 & 0,8 \\
Apresenta baixo rendimento & 4 & 6,0 & 4 & 4,3 \\
Falta de apoio da família & 2 & 3,0 & & 0,8 \\
Baixa autoestima & & & 1 \\
\hline Total & 67 & 100 & 119 & 100 \\
\hline
\end{tabular}

Os dados apresentados na Tabela 2 fomentam que, para as professoras brasileiras, o item desinteresse em aprender é a qualidade mais relacionada ao comportamento desmotivado $(23,8 \%, n=16)$. No que se refere às qualidades do comportamento desmotivado dos alunos na percepção das professoras chilenas, o item distraído obteve a maior frequência: 23 $(19,2 \%)$.

Os dados referentes à percepção do professor quanto ao comportamento motivado ou desmotivado de seus alunos e categorizados nas tabelas apresentadas nas páginas anteriores revelam muitas semelhanças na forma com que o professor, seja brasileiro, seja chileno, avalia seu aluno. Tal afirmação se torna evidente ao se compararem as qualidades apontadas por ambos em cada categorização.

\section{Discussão}

Inicialmente, vale ponderar que este estudo é exploratório e os dados trazidos aqui não retratam na íntegra a realidade dos dois contextos culturais pesquisados. Pode-se dizer, contudo, que a presente pesquisa visou retratar a percepção dos professores participantes, tanto no Brasil quanto no Chile, portanto, os dados aqui obtidos servem de partida para outros estudos.
Goya e colaboradores (2008) destacam que, no contexto escolar, a motivação é observável mediante o comportamento dos professores e dos alunos. Nessa pesquisa, o objetivo versava com o objetivo de verificar a percepção dos professores acerca do comportamento motivado ou desmotivado apresentado por seus alunos. Os dados apresentados nas Tabelas revelaram a visão do professor e a associação que este faz de atitudes e comportamentos emocionais à motivação.

Contudo, muitos dos professores enunciaram como qualidades do aluno motivado o que Bzuneck (2009) afirma com relação a esse aluno, ou seja, aquele que se envolve ativamente nas tarefas pertinentes ao processo de atividade. Com relação às qualidades do aluno desmotivado, o autor ressalta que este faz apenas o mínimo na realização de uma atividade e/ou desiste facilmente quando as tarefas the parecem um pouco mais exigentes. Os dados coletados a partir da entrevista realizada com os professores revelam que estes percebem tais características do comportamento desmotivado.

Outro aspecto que se salienta nas respostas dadas, seja pelo professor chileno, seja pelo professor brasileiro, quanto ao comportamento motivado ou desmotivado para aprender de seus alunos, é a semelhança que ambos apresentam na categorização das qualidades relacionadas tanto a um como a outro 
comportamento. Dos dados obtidos nas quatro escolas, somente na escola pública brasileira a participação não obteve a maior frequência na categorização das qualidades relacionadas ao comportamento motivado. Com relação ao comportamento desmotivado, também foi na escola pública brasileira que apareceu a diferença. Nela, a qualidade desinteresse em aprender obteve a maior frequência dentre as qualidades apontadas como relacionadas ao comportamento desmotivado, enquanto nas demais a maior incidência foi para a distração.

Cabe destacar também o percentual de aproximadamente $7,7 \%$ de qualidades apontadas isoladamente em cada categorização, ou seja, que obtiveram frequência igual a 1. Tal constatação permite levantar a hipótese de que é possível que os professores pesquisados não tenham percebido qualidades idênticas em seus alunos quanto ao que eles consideram ser pertinente ao comportamento motivado ou desmotivado para aprender. Dessa constatação, podese inferir que é possível que esses professores possuíssem um conhecimento teórico pouco suficiente quanto ao entendimento do que seja a motivação para aprender. Essa hipótese recebe ainda mais consistência quando se analisa que, no conjunto das qualidades apontadas pelos professores para caracterizar um aluno motivado ou desmotivado para aprender, estão contidos sentimentos e atitudes que não se referem diretamente à motivação, tais como: dificuldade de aprendizagem, atitude de partilha, dentre outros.

Nessa perspectiva, discute-se o fato de que o professor é um interlocutor que permite o diálogo entre aluno, espaço escolar e conhecimento (Manchope, 2010); independente de sua realidade contextual é ele que em primeira instância torna a escola um espaço atrativo à aprendizagem. Assim sendo, a percepção que esse professor tem acerca da motivação ou desmotivação para aprender de seus alunos pode ter relação com um melhor aproveitamento/êxito escolar desses alunos (Anderman \& Anderman, 1999; Deci \& Ryan, 2000; Guimarães, 2004).

Os resultados apresentados e discutidos com base nesta pesquisa revelaram um dos elementos que merecem atenção especial por parte dos responsáveis pela educação: a formação do professor. $\mathrm{O}$ conhecimento na área da motivação para aprender se apresenta como fator de suma importância, dada a possibilidade que oferece de capacitar o professor a utilizar meios que o auxiliarão no seu fazer pedagógico, tornando o processo de ensino e aprendizagem mais eficiente. Nesse sentido, Bzuneck e Guimarães (2004) sugerem aos professores estratégias para a motivação, tais como, proporcionar tarefas desafiadoras e dosadas às capacidades dos alunos, pois afirmam que todo o desafio desequilibra e incentiva o trabalho mental e afugenta pensamentos de comparação com os outros.

A presente pesquisa, por ser exploratória, apresenta limitações, uma delas se configura em razão do número de professores que concordaram em participar da pesquisa. Alguns professores, embora tenham demonstrado simpatia, se recusaram a participar, e a alegação mais recorrente foi a falta de tempo disponível para fazê-lo. As implicações psicoeducacionais da prática do professor são reconhecidamente relevantes na dinâmica do processo motivacional do aluno. Nessa direção, em investigações futuras seria pertinente a busca de possíveis relações entre a percepção do professor quanto ao aluno motivado e o perfil motivacional do aluno. Assim, há que mencionar a necessidade de se buscarem formas mais precisas de se mensurar a percepção do professor quanto ao perfil motivacional de seu aluno.

Outro limitador é o fato da inexistência, até o presente momento, de estudos chilenos que tenham investigado a motivação para aprender na educação básica. Por isso, os dados aqui apresentados são gerais, não sendo possível comparar as evidências levantadas com estudos anteriores, em especial, estudos realizados com professores da educação básica acerca da motivação de seus alunos.

Há que se discutir o fato de que, se o professor é capaz de interferir na aprendizagem do aluno, seja por meio de feedbacks positivos seja por negativos, avaliações gerais e outras formas de ações pedagógicas e comportamentos (Brophy, 1999; Deci \& Ryan, 2000; Hancock, 2002, dentre outros), o que dizer do impacto dessa intervenção quando o ponto de partida do professor é sua percepção, que lhe aponta para "classificar" o aluno motivado ou desmotivado? Quais seriam as implicações psicoeducacionais para o aluno ao longo de sua vida escolar? Evidentemente essas questões merecem uma investigação futura mais aprofundada.

Conclui-se, portanto, que o professor possui um papel imprescindível na motivação para aprender de seus alunos e que o contato individual que ele mantém com o discente, associado ao suporte teórico dos estudos relativos à motivação para aprender e às estratégias de aprendizagem, favorecera a qualidade do processo de ensino e aprendizagem quer seja no Brasil, quer seja no Chile. 


\section{Referências}

Ames, C. (1992). Classrooms: goals, structures, and student motivation. Journal Educational Psychology, 84, 261-271.

Anderman, H. L., \& Anderman, E. M. (1998). Social predictors of changes in students' achievement goal orientations. Contemporary Educational Psychology, 25, 21-37.

Bandura, A., Azzi, R. G., \& Polydoro, S. (2008). Teoria social cognitiva: conceitos básicos. Porto Alegre: Artmed.

Baumeister, R. F., \& Leary, M. R. (1995). The need to belong: desire for interpersonal attachments as a fundamental human motivation. Psychological Bulletin, 117(3), 497- 529.

Boruchovitch, E. (1999) Estratégias de aprendizagem e desempenho escolar: considerações para a prática educacional. Psicologia: Reflexão e Crítica, 12(2), 361376.

Boruchovitch, E. (2004). A auto-regulação da aprendizagem e a escolarização inicial. Em E. Boruchovitch \& J. A. Bzuneck, J. A. (Orgs.), Aprendizagem: processos psicológicos e o contexto social na escola (pp. 55-88). Petrópolis: Vozes.

Bronson, M. B. (2000). Self-regulation in early childbood: nature and nurture. New York: The Guilford Press.

Brophy, J. (1981). Teacher praise: a functional analysis. Review of Educational Research, 5, 5-32.

Brophy, J. (1999). Research on motivation in Education: past, present, and future. Em T. Urdan (Ed.). Advances in Motivation and Achievement, 11, 144.

Bzuneck, J. A. (2009). A motivação do aluno: aspectos introdutórios. Em E. Boruchovith, \& J. A. Bzuneck (Orgs.). A motivação do aluno: contribuições da psicologia contemporânea (pp. 9-36). Petrópolis, RJ: Vozes.

Bzuneck, J. A. (2010). Como motivar os alunos: sugestões e práticas. Em E. Boruchovitch, J.A. Bzuneck \& S.É.R. Guimarães, (Orgs.). Motivação para aprender: aplicações no contexto educativo (pp.1342). Petrópolis, RJ: Vozes.

Bzuneck, J. A., \& Guimarães, S. É. R. (2007). Estilos de professores na promoção da motivação intrínseca: reformulação e validação de instrumento. Psicologia: Teoria e Pesquisa, 23, 415422.
Bzuneck; J. A., \& Guimarães, S. É. R. (2004). Aprendizagem escolar em contextos competitivos. Em E. Boruchovitch \& J. A. Bzuneck (Orgs.). Aprendizagem: contextos psicológicos e contexto social na escola (pp. 251-277). Petrópolis, RJ: Vozes.

Bzuneck; J. A., \& Guimarães, S. É. R. (2010). A promoção da autonomia como estratégia motivacional na escola: uma análise teórica e empírica. Em E. Boruchovitch, J. A. Bzuneck \& S.É.R. Guimarães (Orgs.). Motivação para aprender: aplicações no contexto educativo (pp. 43-70). Petrópolis, RJ: Vozes,

Cardoso, E. T. (2008). Motivaşão escolar e o lúdico: o jogo RPG como estratégia pedagógica para o ensino de história (Dissertação de Mestrado). Campinas: Universidade Estadual de Campinas.

Chile (1992). Diário Oficial. Estatuto de los Profesionales de la Educacion. Decreto Supremo n. 453.

Costa, G. D. F. (2005). relações entre as orientações motivacionais e o desempenho escolar de alunos da $7^{a}$ série do ensino fundamental em matemática, na resolução de equações do $1^{\circ}$ grau. (Dissertação de Mestrado). Campinas: Universidade Estadual de Campinas Faculdade de Educação.

Cunha, C. A., Sisto, F. F., \& Machado, F. (2006). Dificuldade de aprendizagem na escrita e $\mathrm{O}$ autoconceito num grupo de crianças. Avaliação Psicológica, 5(2), 153-157.

Deci, E. L., \& Ryan, R. M. (1985). Intrinsic motivation and self-determination in buman behavior. Nova York: Plenum Press.

Deci, E. L., \& Ryan, R. M. (1987). The support of autonomy and the control behavior. Journal of Personality and Social Psychology, 53, 1024-1037.

Deci, E. L., \& Ryan, R. M. (2000).The "what" and "why" of goal pursuits: human needs and selfdetermination of behavior. Phychological Inquiry, 11 (4), 227-268.

Delors, J. (1999). Educação: um tesouro a descobrir ( $3^{\mathrm{a}}$ ed.). SP: Cortez.

Dias, T. L., Enumo, S. R. F., \& Turini, F. A. (2006). Avaliação do desempenho acadêmico de alunos do ensino fundamental em Vitória, Espírito Santo. Estudos de Psicologia - Campinas, 23(4), 381-390.

Fernandez- Gonzalez, O. M., Martinez-Conde Beluzan, M., \& Melipillan Araneda, R. (2009). Estrategias de aprendizaje y autoestima: su relacion con la 
permanencia y desercion universitaria. Estudios Pedagógicos - Valdivia, 35(1), 27-45.

Genari, C. H. M. (2006). Motivação no contexto escolar e desempenho acadêmico (Dissertação de Mestrado). Campinas: Universidade Estadual de Campinas.

Goya, A., Bzuneck, J. A., \& Guimarães, S. É. R. (2008). Crenças de eficácia de professores e motivação de adolescentes para aprender Física. Psicologia Escolar $e$ Educacional, 12(1), 51-67.

Guimarães, S. E. R. (2004). Necessidade de pertencer: um motivo humano fundamental. Em E. Boruchovitch \& J. A. Bzuneck (Orgs.). Aprendizagem: processos psicológicos e o contexto social na escola (pp. 177-199). Petrópolis, RJ: Vozes.

Guimarães, S. É. R., Bzuneck, J. A., \& Boruchovitch, E. (2003). Estilos motivacionais de professores: propriedades psicométricas de um instrumento de avaliação. Psicologia: Teoria e Pesquisa, 19(1), 17-24.

Hagger, M. S., Chatzisarantis, N. L. D., \& Harris, J. (2006). From psychological need satisfaction to intentional behavior: testing a motivational sequence in two behavioral contexts. Personality and Social Psychology, 32, 131-148.

Hancock, D. R. (2002). Influencing graduate stidents classroom achievement, homework habits and motivation to learn with verbal praise. Educational Research, 44, 81-95.

Henderlong, J., \& Lepper, M. R. (2002). The effects of praise on children's intrinsic motivation: a review and synthesis. Psychological Bulletin, 128(5), 774-795.

Lei $n^{\circ}$. 9.394, 20 de dezembro de 1996. Estabelece as diretrizes e bases da educação nacional. Diário Oficial da União. Brasília, DF.

Machado, A. C. T. A. (2009). Interação professor-alunos: preferência por autonomia ou controle (Dissertação Mestrado). Londrina: Universidade Estadual de Londrina.

Maehr, M. L. (1984). Meaning and motivations: toward a theory of personal investment. Em R. Ames \& C. Ames (Orgs.). Research on Motivation in Education. (pp. 115-144). Orlando, FLA: Academic Press.

Maieski, S., \& Oliveira, K. L. (2011). Entrevista aberta com professores para constatar a percepsão dos docentes quanto ao comportamento motivado ou desmotivado para aprender de seus alunos. Manuscrito não publicado do Programa de Mestrado da Universidade Estadual de Londrina.

Manchope, E. C. P. (2010). Reflexões sobre a formação de professores na atualidade Em M. L. S.

Psico-USF, Bragança Paulista, v. 18, n. 1, p. 53-64, jan./ abril 2013
Szymanski (Org.). Aprendizagem e ação docente (pp. 85-98). Cascavel: EDUNIOESTE.

Martinelli, S. C., \& Bartholomeu, D. ( 2007). Escala de Motivação Acadêmica: uma medida de motivação extrínseca e intrínseca. Avaliação Psicológica, 6(1), 21-31.

McComs, B. L.; Pope, J. E. (1994). Motivating hard to reach students. American Psychological Association. Washington. DC.

Nelson-Legall, S., \& Glor-Scheidb. (1986). S. Academic help seeking and peer relations in school. Contemporary Educational Psychology, 11, 187-193.

Neves, E. R. C., \& Boruchovitch, E. (2007). Escala de avaliação da motivação para aprender de alunos do ensino fundamental (EMA). Psicologia: Reflexão e Critica, 20(3), 406-413.

Osterman, K.F. (2000). Students' need for belonging in the school community. Review of Educational Research, 70(3), 323-367.

Paiva, M. L. M. F., \& Boruchovitch, E. (2010). Orientações motivacionais, crenças educacionais e desempenho escolar de estudantes do ensino fundamental. Psicologia em Estudo, 15(2), 381-389.

Peres, J. G. (2011). Perfis motivacionais e engajamento de adolescentes nas tarefas escolares em casa (Dissertação de Mestrado). Londrina: Universidade Estadual de Londrina.

Pintrich P, R., \& Schunk, D. H. (2002). Motivation in education - theory, research and applications. New Jersey: Merril Prentice Hall.

Reeve, J., Deci, E. L., \& Rayn, R. M. (2004). Selfdeterminations theory. A dialectical framework for understand sociocultural influences on student motivation. Em D.M. Mcinerney \& S. Vanetten (Orgs.). Big Theories Revisited (pp. 31-58). Connecticut: Age Publishing.

Rodrigues, L. C., \& Barrera, S. D. (2007). Auto-eficácia e desempenho escolar em alunos do ensino fundamental. Psicologia em Pesquisa - Juiz de Fora, 1(2), 41-53.

Rosas, R.., Perez-Salas, C. P., \& Olguin, P. (2010). Pizarras interactivas para un aprendizaje motivado en niños con paralisis cerebral. Estud. Pedagóg., Valdivia, 36(1). Disponível em: $<$ http://www.scielo.cl/scielo.php?script=sci_artte xt\&pid=S071807052010000100011\&lng=pt\&nrm=iso $>$. Acesso em: 24 jun. 2011. 
Rufini, S. E., Bzuneck, J. A., \& Oliveira, K. L. (2011). Estudo de validação de uma medida de avaliação da motivação para alunos do ensino fundamental. Psico-USF, 16(1), 1-9.

Ryan, R. M., \& Decy, E. L. (2006) Self-Regulation and the problem of human autonomy: does psychology need choice, self-determination, and will? Journal of Personality, 74(6), 1557-1585.

Saviani, D. (2008). História das ideias pedagógicas no Brasil ( $2^{\mathrm{a}}$ ed.). Campinas: Autores Associados.

Siqueira, L. G. G., \& Wechsler, S. M. (2006). Motivação para a aprendizagem escolar: possibilidade de medida. Avaliação Psicológica, 5(1), 21-31.

Souza, L. F. N. I., \& Brito, M. R. F. de. (2008). Crenças de auto-eficácia, autoconceito e desempenho em matemática. Estudos de Psicologia - Campinas, 25(2), 193-201.

Stipek, D. (1998). Motivation to learn: from theory to practice ( $2^{a}$ ed.). Boston: Allyn and Bacon.
Szymanski, M. L. S. (2010). Familiaridade com a tarefa: até onde pode favorecer o desenvolvimento cognitivo. Em M. L. S. Szymanski (Org.). Aprendizagem e ação docente (pp. 13-30). Cascavel: EDUNIOESTE.

Villalobos, M. V. P., Mujica A. D., González-Pienda'J. A., Núñez Pérez, J. C., \& Rosário, P. (2009). Escala de Metas de Estudio Para Estudiantes Universitarios. Interamerican Journal of Psychology, 43(3), 449-455.

Zolnier, M. C. A. P. (2007). Lingua inglesa: expectativas e crenças de alunos e de uma professora do ensino fundamental (Dissertação de Mestrado). Campinas: Universidade Estadual de Campinas.

Zulma Lanz, M. (2006). Aprendizaje autorregulado: el lugar de la cognición, la metacognición y la motivación. Estudos Pedagógicos, 32(2), 121-132.

Recebido em: 14/03/2012

Reformulado em: 23/01/2013

Aprovado em: 20/02/2013 
Sobre os autores:

Sandra Maieski é pedagoga com especialização em Educação Infantil e mestrado em Educação pela Faculdade de Educação da Universidade Estadual de Londrina.

Katya Luciane de Oliveira é psicóloga, mestre em Psicologia pelo Programa de Pós-Graduação Stricto Sensu em Psicologia da Universidade São Francisco, doutora em Psicologia, Desenvolvimento Humano e Educação pela Unicamp e professora adjunta doutora do curso de Psicologia e do Programa de Mestrado em Educação da Universidade Estadual de Londrina.

José Aloyseo Bzuneck é filósofo, com doutorado em Psicologia Escolar e do Desenvolvimento Humano pela Universidade de São Paulo. É professor sênior na Universidade Estadual de Londrina, onde atua no Programa de Mestrado em Educação.

\section{Contato com os autores:}

Universidade Estadual de Londrina Avenida São Paulo, 651 - CEP 86010-970 - Centro - Londrina/PR, Brasil.

E-mail: irmsandra@yahoo.com.br 